\title{
Analysis of the machinability when milling AlSi10Mg additively manufactured via laser-based powder bed fusion
}

\author{
Marco Zimmermann ${ }^{1} \cdot$ Daniel Müller ${ }^{1} \cdot$ Benjamin Kirsch ${ }^{1} \cdot$ Sebastian Greco ${ }^{1} \cdot$ Jan C. Aurich ${ }^{1}$
}

Received: 14 August 2020 / Accepted: 9 November 2020 / Published online: 27 November 2020

(C) The Author(s) 2020

\begin{abstract}
Laser-based powder bed fusion (L-PBF) is a promising technology for the production of near net-shaped metallic components. The high surface roughness and the comparatively low-dimensional accuracy of such components, however, usually require a finishing by a subtractive process such as milling or grinding in order to meet the requirements of the application. Materials manufactured via L-PBF are characterized by a unique microstructure and anisotropic material properties. These specific properties could also affect the subtractive processes themselves. In this paper, the effect of L-PBF on the machinability of the aluminum alloy AlSi10Mg is explored when milling. The chips, the process forces, the surface morphology, the microhardness, and the burr formation are analyzed in dependence on the manufacturing parameter settings used for L-PBF and the direction of feed motion of the end mill relative to the build-up direction of the parts. The results are compared with a conventionally cast AlSi10Mg. The analysis shows that L-PBF influences the machinability. Differences between the reference and the L-PBF AlSi10Mg were observed in the chip form, the process forces, the surface morphology, and the burr formation. The initial manufacturing method of the part thus needs to be considered during the design of the finishing process to achieve suitable results.
\end{abstract}

Keywords Laser-based powder bed fusion $\cdot$ Milling $\cdot$ Machinability $\cdot$ Surface quality $\cdot$ Surface integrity $\cdot$ Burr formation

\section{Introduction}

In laser-based powder bed fusion (L-PBF), components are produced from a powdery raw material by the defined layerby-layer joining of individual volume elements. This manufacturing principle enables new possibilities for the user with regard to the freedom in design, the manufacturing of highly customized parts, and the tailoring of products to the requirements of particular applications [1-3]. In recent years, intensive research has been carried out to understand the physical principles of L-PBF [4-6] and to study the influence of the process management on the properties of the manufactured components [7-9]. As a result, the degree of maturity of LPBF has been significantly improved. Today, it is used in

Marco Zimmermann

marco.zimmermann@mv.uni-kl.de

1 Institute for Manufacturing Technology and Production Systems, Technische Universität Kaiserslautern, Gottlieb-Daimler-Str., D-67663 Kaiserslautern, Germany several industrial sectors not only for prototyping but also for the manufacturing of customized parts $[10,11]$.

The surface qualities and dimensional accuracies of laserbased powder bed-fused (hereafter also abbreviated as LPBF) parts, however, are usually still insufficient for a direct application of the parts $[12,13]$. Depending on the manufacturing parameters used for L-PBF, typically documented average surface roughness values $\mathrm{Ra}$ of as-built parts are in the range of $\mathrm{Ra}=3-40 \mu \mathrm{m}[14,15]$, and common dimensional errors are between 0.01 and $34 \%$ of the target values $[11,16]$. Therefore, functional surfaces of L-PBFmanufactured components usually require a finishing by means of a subtractive process such as milling, grinding, laser machining, or polishing in order to improve the part quality characteristics [17-19]. Machining processes are known to be well-suited for the production of adequate functional surfaces at cast or wrought components. It is therefore obvious to also finish additively manufactured components by machining. However, the properties of L-PBF materials significantly differ from cast or wrought components due to the large temperature gradients in the material during L-PBF and the complex heat transfer to the material due to the cyclic processing [12]. 
These specific process conditions of L-PBF result in a unique, anisotropic, and fine-grained microstructure, which improves strength and toughness $[12,20]$. The L-PBF process conditions are accompanied by anisotropic material properties, large and highly inhomogeneous residual stresses, and a porous material structure including unmelted or only partially melted powder particles [21-23]. As a result, the machinability of parts manufactured via L-PBF could significantly differ from wrought or cast metals despite the same chemical composition.

Grove et al. [24] investigated the machinability of a titanium alloy manufactured via laser-based powder bed fusion. They found different mechanisms of chip formation (material manufactured via L-PBF: continuous chips, cast reference material: serrated chips), higher forces during the milling of the material manufactured via L-PBF, and a different wear behavior of the tools. Only the tools used for the milling of the L-PBF material showed severe chipping. The surface roughness of the finished additively manufactured workpieces was higher, and the stress state of the surface residual stresses depends, contrary to the reference, strongly on the evaluation direction. Tensile stresses were measured perpendicular to the feed motion of the tool and compressive stresses parallel to the feed motion [24]. Milton et al. [13] determined higher forces when milling a titanium alloy produced by means of L-PBF in comparison to the hot-rolled reference and also a stronger work hardening behavior, which resulted in different hardness depth profiles in the surface layer. Polishetty et al. [25] compared the results of turning between a wrought and a L-PBF titanium alloy. They detected lower roughness values on the surfaces of the specimens made via L-PBF. The turning of these specimens caused higher forces. A rise of cutting speed increased the difference [25]. Le Coz et al. [26] investigated the machinability when micro cutting a cast and a L-PBF titanium alloy. The surface integrity and the chip morphology were not affected by the manufacturing method. However, the forces were up to $24 \%$ higher in machining the L-PBF material, depending on the cutting condition used [26]. Sartori et al. [27] found more intense crater wear and flank wear on the tools used to mill a titanium alloy made via L-PBF. They concluded that the machinability of this material is worse in comparison to the wrought reference [27]. Alexeev et al. [28] showed that the magnitude of the cutting force depends on the direction of feed motion of the end mill relative to the build-up direction (BUD) of the workpieces (AISI $316 \mathrm{~L}$ ) during LPBF. Milling perpendicular to the BUD caused higher forces than milling parallel to the direction of build-up [28]. Differences with respect to the results of finishing were also documented between a L-PBF Inconel 718 and a cast reference in grinding. Regarding the additively manufactured material, the grinding wheel wear was less, the surfaces were rougher, and the hardness in the surface layer was smaller than at the cast specimens [29].
Ullah et al. [30] studied the thrust forces when drilling a L$\mathrm{PBF}$ and wrought AlSi10Mg. The magnitude of the thrust forces depended on the manufacturing parameters used for $\mathrm{L}-\mathrm{PBF}$, which affect the properties of the material. A lower material hardness led to higher thrust forces. It was assumed that this is due to greater plastic deformation of the material during chip formation and the continuous chips that were formed. The thrust forces during the drilling of the wrought reference material were smaller compared to the aluminum alloy manufactured via L-PBF [30]. Struzikiewicz et al. [31] investigated the machinability of AlSi10Mg workpieces. Turning the L-PBF material caused lower forces than the cast reference material and a higher arithmetic mean roughness, except for the use of the minimum feed $(0.058 \mathrm{~mm} / \mathrm{rev})$ considered. Here, the surfaces of the workpieces made by means of L-PBF were smoother. Burrs were detected on the additively manufactured workpieces but not on the cast workpieces [31].

In conclusion, powder bed fusing significantly affects the machinability of the so far investigated materials. The nature of this influence seems to depend not only on the manufacturing parameter settings used for L-PBF but also on the machining process applied for finishing and the manufacturing method of the reference material under consideration. For the application of L-PBF AlSi10Mg parts, knowledge of the influence of L-PBF on the subsequent machining process is of great importance in order to be able to control the part quality during finishing. In the present paper, the machinability of LPBF workpieces made of the aluminum alloy AlSi10Mg is explored when milling. This alloy is a traditional cast alloy that is frequently used in the aerospace and automotive industry due to its good mechanical properties, light weight, and small coefficient of thermal expansion [32,33]. The chip morphology, the resultant forces, the surface roughness, the microhardness, and the burr formation are analyzed in dependence on the manufacturing parameters used for L-PBF and the direction of feed motion of the end mill relative to the build-up direction of the workpieces. The effect of L-PBF on the machinability of AlSi10Mg is evaluated by comparing the results with cast reference specimens.

\section{Experimental design}

\subsection{Manufacturing of the AlSi10Mg specimens}

The workpieces produced by L-PBF were manufactured by using the SLM $^{\circledR} 280$ HL Twin by SLM Solutions Group AG. ${ }^{1}$ This system is equipped with a heated building platform, a

\footnotetext{
${ }^{1}$ Naming of specific manufacturers is done solely for the sake of completeness and does not necessarily imply an endorsement of the named companies nor that the products are necessarily the best for the purpose.
} 
maximum building volume of $280 \times 280 \times 350 \mathrm{~mm}$, and two $400 \mathrm{~W}$ lasers. The dimensions of the workpieces and their orientation on the building platform during L-PBF are shown in Fig. 1.

The workpieces were produced with two different process parameter combinations L-PBF1 and L-PBF2, which differ in terms of their layer thickness and the scanning speed of the laser (Table 1). The increased layer thickness of L-PBF1 is representative for a reduced exposure time during L-PBF, which is halved in the present case, and thus for a more economic process. For both process parameter combinations, a $67^{\circ}$ rotation of the scan vectors from layer to layer was chosen as the scanning strategy, the hatch spacing was $170 \mu \mathrm{m}$, and the building platform was heated to $150{ }^{\circ} \mathrm{C}$ during L-PBF.

The L-PBF workpieces were not heat-treated after L-PBF; they were milled as-built. This allows for the evaluation of the influence of L-PBF on machinability. The reference material was produced by casting and a subsequent heat treatment (T6), which is a common manufacturing chain for the production of AlSi10Mg components.

\subsection{Milling}

Dry side milling was performed on a 5-axis machining center (DMU 70 eVolution $^{1}$ ) with the experimental setup given in Fig. 2a. On each workpiece, two $90^{\circ}$ shoulders were manufactured using solely up milling and solely down milling, respectively (Fig. 2b).

The tools used were cemented carbide end mills (K.-H. Müller Präzisionswerkzeuge ${ }^{1}$ : AluMax) with a diameter $\mathrm{d}$ of $8 \mathrm{~mm}$ and three teeth (Fig. 3). The end mills had a helix angle $\delta$ of $45^{\circ}$, a tool orthogonal rake angle $\gamma$ of $13^{\circ}$, a first tool orthogonal clearance $\alpha_{1}$ of $2^{\circ}$, and a second tool orthogonal clearance $\alpha_{2}$ of $10^{\circ}$. The end mills were coated with a zirconium nitride coating. The cutting edge radius of the tools after coating amounted to $r_{\beta}=9 \pm 0.9 \mu \mathrm{m}$, and the form-factor was $K=1.037 \pm 0.054$. The cutting edge geometry was measured using a fringe projection sensor (GFM MikroCAD Plus ${ }^{1}$ ).

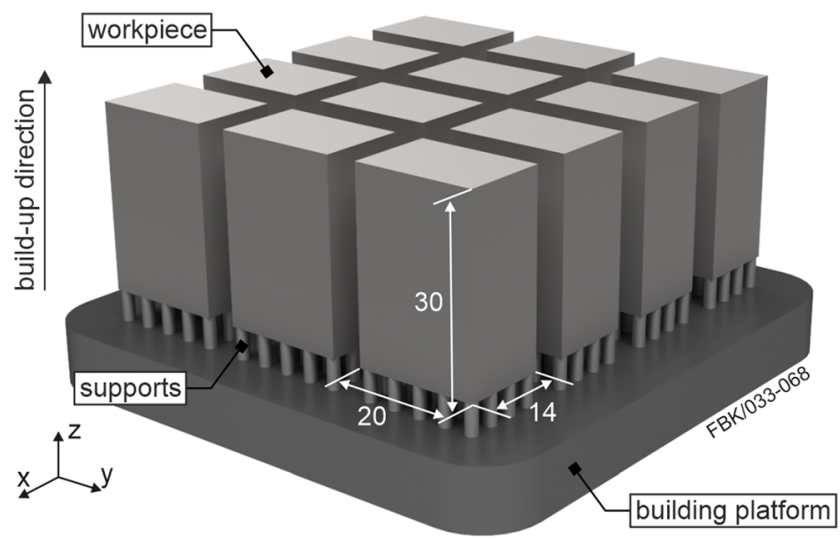

Fig. 1 Workpiece dimensions and orientation of the workpieces on the building platform during L-PBF
Table 1 Process parameter combinations used for L-PBF

\begin{tabular}{lll}
\hline Process parameters & L-PBF1 & L-PBF2 \\
\hline Scanning strategy (bulk) & $67^{\circ}$ alternating & \\
Hatch spacing $h$ in $\mu \mathrm{m}$ & 170 & \\
Building platform temperature in ${ }^{\circ} \mathrm{C}$ & 150 & 30 \\
Layer thickness $t$ in $\mu \mathrm{m}$ & 60 & \\
Laser power $P$ in $W$ & & 300 \\
Contour & 370 & 300 \\
$\quad$ Bulk & 300 & \\
Scanning speed $v_{\mathrm{S}}$ in $\mathrm{mm} / \mathrm{s}$ & & 730 \\
$\quad$ Contour & 860 & 730 \\
Bulk & 750 & \\
\hline
\end{tabular}

The process parameter settings used are listed in Table 2 . All samples were milled at a constant cutting speed $v_{c}$ as well as axial $a_{p}$ and radial $a_{e}$ infeed. The milling kinematics (up milling and down milling), the direction of feed motion of the end mill relative to the build-up direction (parallel $v_{f \|}$ and perpendicular $\mathrm{v}_{\mathrm{f}_{\perp}}$ (Fig. 2b)) and the feed per tooth $\mathrm{f}_{\mathrm{z}}$ were varied. The $f_{z}$ variation was only carried out for the reference material and for L-PBF2. L-PBF1 was milled with a feed per tooth of $\mathrm{f}_{\mathrm{z}}=0.06 \mathrm{~mm}$. Prior to the formation of significant signs of wear or adhesions on the tool (Fig. 3), new end mills were used for milling in order to avoid a significant effect of these phenomena on the results. All milling tests were carried out three times respectively.

\subsection{Characterization methods}

The chemical composition of the L-PBF materials and the reference material was measured via energy dispersive $\mathrm{X}$-ray spectroscopy (EDS). Three measurements were carried out for statistical verification, respectively. To determine the relative density $\rho$ of the materials, the dimensions of the specimens were measured in each of the three directions, as well as the weight. For this purpose, three specimens of each manufacturing method of the material were milled on each side using an identical cutting condition. This results in a defined surface structure and material volume. The weight of these specimens was measured using a precision balance (accuracy: $\pm 0.001 \mathrm{~g}$, Kern \& Sohn GmbH, EMB 200-3 ${ }^{1}$ ), the dimensions by means of a digital vernier height gauge (accuracy: $\pm 0.01 \mathrm{~mm}$, BZT Maschinenbau $\mathrm{GmbH}^{1}$ ). The density $\rho_{\mathrm{m}}$ so determined was divided through the density of a completely dense AlSi10Mg specimen (taken from literature: $\rho_{\mathrm{d}}=2.68 \mathrm{~kg} / \mathrm{dm}^{3}$ [34]) in order to calculate the relative density $\left(\rho=\rho_{\mathrm{m}} / \rho_{\mathrm{d}}\right)$.

The forces in $\mathrm{x}^{-}, \mathrm{y}-$, and $\mathrm{z}$-direction during milling were measured using a rotating dynamometer (Kistler $9123 \mathrm{C}^{1}$ ) with a sampling rate of $15 \mathrm{kHz}$. The arithmetic mean of the root mean square (RMS) values of these forces was 

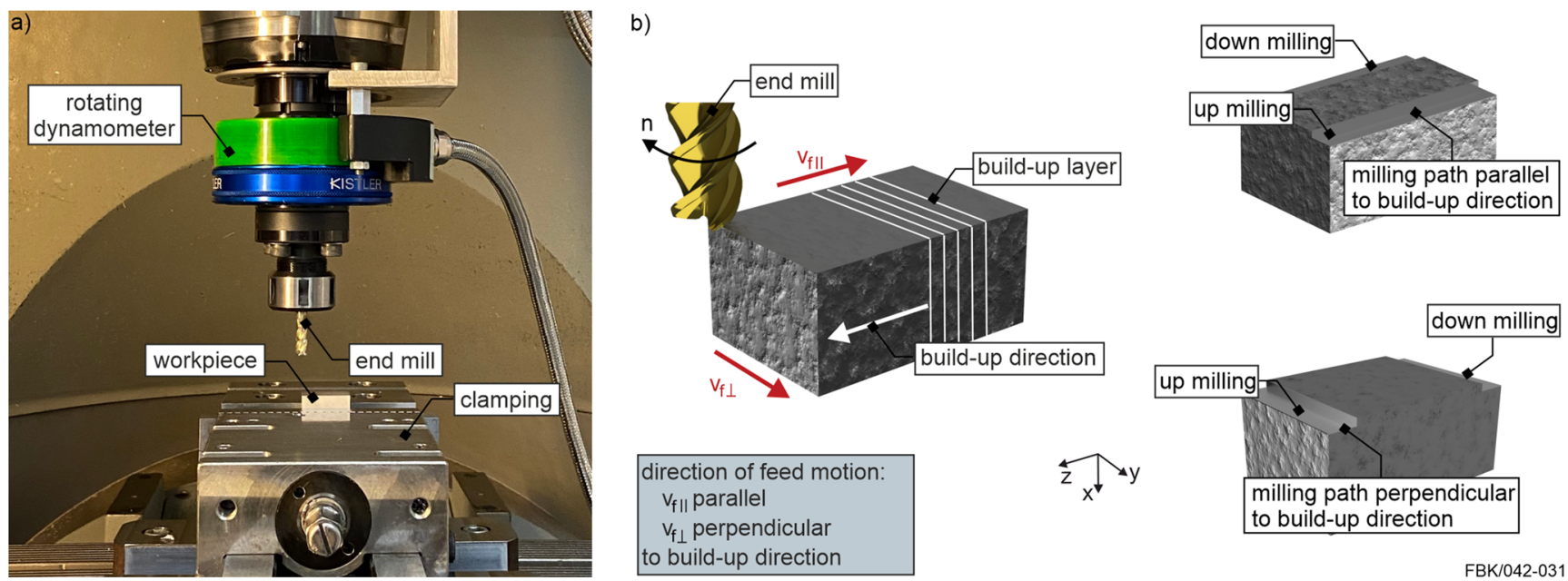

Fig. 2 a Experimental setup and $\mathbf{b}$ relation between the direction of feed motion of the end mill and the build-up direction

calculated over the time that was required to mill a $90^{\circ}$ shoulder (Fig. 2b). These three averaged values were vectorially added in order to determine the resultant force $\mathrm{F}_{\mathrm{z}}$, which is used to evaluate the forces. The surface roughness of the specimens prior to milling and after milling was measured by means of a stylus instrument (MarSurf XR20 GD120 ${ }^{1}$ ). Three measurements were carried out on each surface considered. Regarding the as-built respectively as-cast workpieces, these three measurement positions were randomly selected. On the milled surfaces, however, the roughness was measured each within three specific areas. The measurement positions were located in the vicinity of the left and right border of the width of the milled surface and approximately in the middle of the surface. Possible effects of the varying undeformed chip thickness across the width of cut, which matches the width of the milled surface, on the roughness can thus be considered within the investigations. Each measurement was carried out in the direction of feed travel of the tool. A measuring length of $5.6 \mathrm{~mm}$ and a Gaussian filter with a cutoff wavelength of $\lambda_{c}=0.8 \mathrm{~mm}$ (to eliminate the waviness) were applied. The surface roughness was specified via the arithmetic mean roughness Ra.
Moreover, scanning electron microscope (SEM, FEI Quanta $600^{1}$ ) images were captured from the surfaces in order to qualitatively analyze the surfaces generated. Backscatter electrons (BSE) were detected. The edges of the workpieces were investigated with regard to possibly formed burrs by means of light microscopy. Sections were made from the workpieces prior to milling and after milling. These sections were prepared metallographically. A Kroll etching agent (2.5\% nitric acid $\mathrm{HNO}_{3}, 2.5 \%$ hydrofluoric acid $\mathrm{HF}$, rest water; etching time $50 \mathrm{~s}$ ) was used to visualize the melt borders. Keller's etching agent (2.5\% nitric acid $\mathrm{HNO}_{3}, 1.5 \%$ hydrochloric acid $\mathrm{HCl}, 1 \%$ hydrofluoric acid $\mathrm{HF}$, rest water; etching time $16 \mathrm{~s}$ ) was used to reveal the microstructure of the materials. The microhardness was measured on the sections with a Vickers indenter using the microhardness tester Buehler MicroMet $5100^{1}$. A load force of $10 \mathrm{gf}$ (HV0.01; $0.098 \mathrm{~N}$ ) was used for the generation of the hardness depth profiles. The measurements were carried out six times following DIN EN ISO 6507-1 [35]. The chip form and chip morphology were analyzed using a reflected-light microscope and a scanning electron microscope.

The uncertainty of the measurement results is indicated via the average standard deviation $\bar{\sigma}$. To determine the average
Fig. 3 Cutting edges of the end mills. a Before milling. b After milling

Table 2 Process parameters used for side milling

Process parameters

Depth of cut $a_{p}$ in mm

Width of cut $a_{e}$ in mm 4

Cutting speed $v_{c}$ in $\mathrm{m} / \mathrm{min} \quad 250$

$\begin{array}{llll}\text { Feed per tooth } f_{z} \text { in } \mathrm{mm} & 0.03 & 0.06 & 0.09\end{array}$

standard deviation, the standard deviations were first calculated from the three repetitions of each investigation. Then, the arithmetic mean was calculated from all standard deviations, which were determined at a specific feed per tooth for L-PBF1 and L-PBF2, respectively, the reference.

\subsection{Characterization of the specimens}

In Fig. 4, SEM images of the as-built surfaces and the chemical composition of the L-PBF1 and L-PBF2 specimens are shown. Etched micrographs, the microhardness of the L-PBF AlSi10Mg, and the ratio of the melt path height to the melt path width are illustrated in Fig. 5.

The structure of the as-built surfaces of both process parameter combinations differs in dependence on their orientation in the powder bed. Surfaces perpendicular to the build-up direction (workpiece xy-plane) show crater-like structures. The roughness of these surfaces is $\mathrm{Ra}=3.8 \pm 0.2 \mu \mathrm{m}$ for $\mathrm{L}$ PBF1 and $\mathrm{Ra}=3.7 \pm 0.1 \mu \mathrm{m}$ for L-PBF2. Adhesions of powder particles that were not completely melted during L-PBF are present on surfaces oriented parallel to the build-up direction (xz- and yz-plane). The quantity of adhering powder particles varies between L-PBF1 and L-PBF2. In the case of LPBF1, more and larger agglomerates were formed. Consequently, the surface roughness of L-PBF1 ( $\mathrm{Ra}=9.2 \pm$ $1.4 \mu \mathrm{m})$ is significantly larger compared to L-PBF2 $(\mathrm{Ra}=4.3$ $\pm 0.9 \mu \mathrm{m})$. The etched micrographs show the characteristic scaly microstructure of materials manufactured by L-PBF in the plane parallel to the build-up direction (Fig. 5, right images). The grains are elongated along the BUD. In the plane perpendicular to the build-up direction, the material exhibits a fine-grained microstructure (Fig. 5, images in the middle). The ratio of the width $w$ to the height $h$ of the single melt paths is smaller at L-PBF1 $(1.74 \pm 0.24)$ than at L-PBF2 (2.25 \pm 0.38$)$. This is due to the greater layer thickness (Table 1) used in the manufacture of L-PBF1. Despite this significant difference in the applied layer thickness, both process parameter combinations achieve relative densities of almost $100 \%$ (L-PBF1: $\rho_{\mathrm{L}-}$ PBF $1=99.4 \pm 0.2 \%$, L-PBF2: $\left.\rho_{\mathrm{L}-\mathrm{PBF} 2}=99.9 \pm 0.1 \%\right)$. The relative density is a value that compares the density of the present material with an ideally manufactured material, i.e., a free of any pores and thus completely dense material $(\rho=100 \%)$. The chemical composition and the microhardness of the L-PBF1 and L-PBF2 specimens are very similar; the slight variations are in the range of the respective standard deviation.

In order to increase the dimensional accuracy of the components, the contour of L-PBF workpieces is typically exposed separately from the bulk, often using different process parameters. This has also been realized for the workpieces considered (Table 1). The melt paths of the contour are therefore oriented differently to the bulk of the workpiece (Fig. 6). Due to the positioning of the workpieces on the building platform (Fig. 1), the contour's exposure was performed only on the surfaces parallel to the build-up direction ( $x z-$ and $y z-$ plane), whereas the exposure for the majority of the workpiece's bulk was carried out perpendicular to the build-up direction ( $x y$-plane) using the scanning strategy listed in Table 1.

Figure 7 depicts the as-cast surface, microstructure, relative density, microhardness, and chemical composition of the reference material. The relative density is $\rho_{\text {ref }}=99.6 \pm 0.1 \%$ and is thus in the same range as that of L-PBF1 and L-PBF2. The chemical composition reveals a lower aluminum content (approximately $6 \%$ ) and a higher silicon content (approximately $6 \%$ ) in comparison to the L-PBF AlSi10Mg. Regarding the microhardness, the reference material is $7 \%$ less hard than LPBF1 and L-PBF2. The higher hardness of the L-PBF material is due to the refinement of the microstructure as a result of the high cooling rates in L-PBF [36]. The etched micrographs of the reference material reveal a dendritic structure with agglomerations of silicon particles.

\section{Results and discussion}

\subsection{Chips}

The chip morphology and chip form are important factors in assessing the machinability of a material, as the quality of machined surfaces and the costs for the production process are influenced by them [37]. Figure 8 a depicts the chip form in dependence on the cutting condition applied for the milling of the L-PBF2 specimens perpendicular to the BUD. A change in feed per tooth or the kinematic of milling (up milling or down milling) has no significant effect on the chip form. Solely the chip curl radius differs slightly between down milling and up milling. Some chips generated in up milling have a slightly greater chip curl radius than the chips after down milling. This indicates different stress distributions across the chip cross section due to differing thermo-mechanical loads on the material. In the case of the manufacturing method L-PBF1 and the reference material, an insignificant effect of the examined cutting conditions on the chip form was found just like with L-PBF2.

The manufacturing method of the AlSi10Mg influences the chip form (Fig. 8b). Milling the reference material results in 
Fig. 4 As-built surfaces and chemical composition of the LPBF1 and L-PBF2 specimens

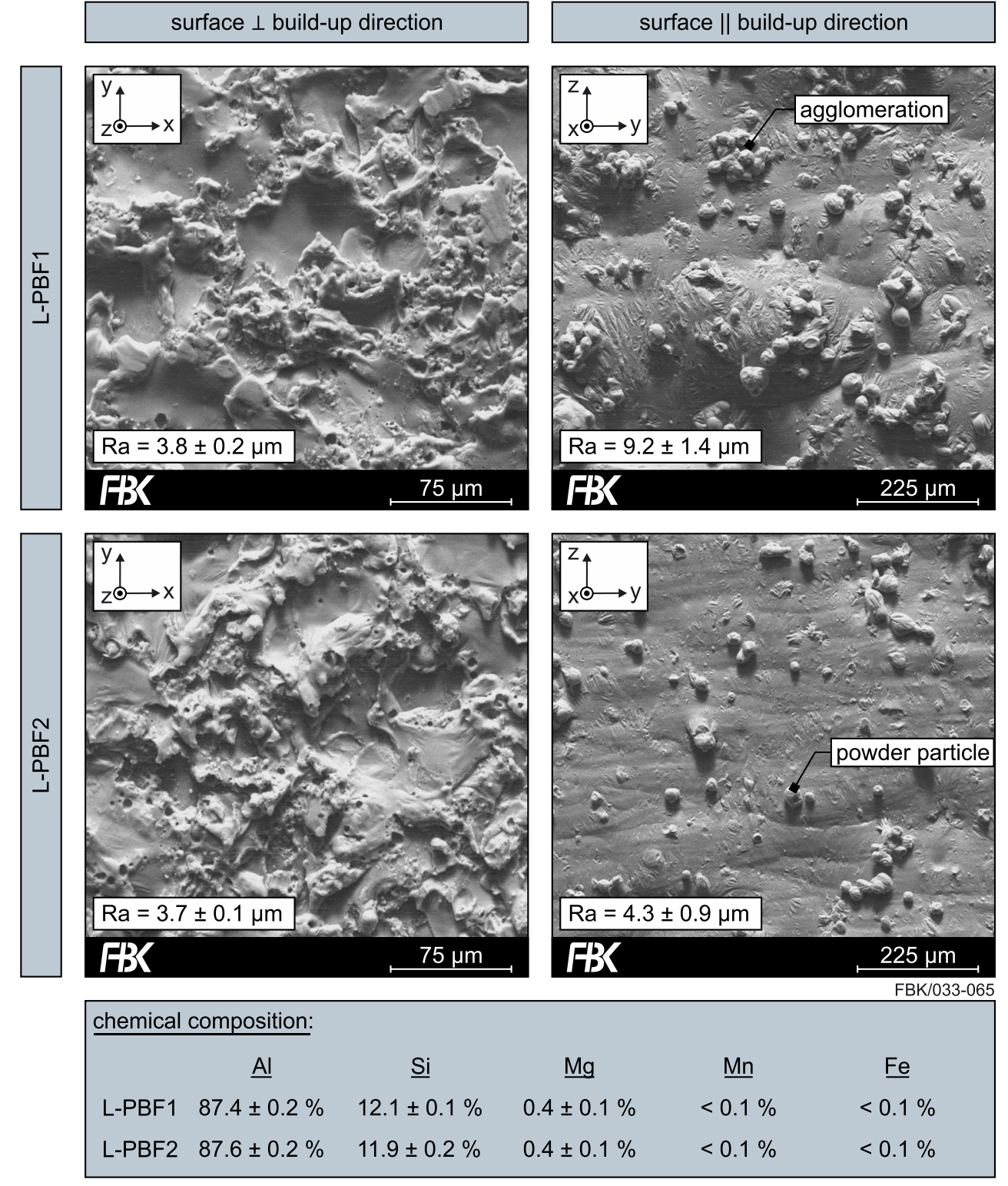

discontinuous chips. Spiral chip segments were observed for both L-PBF1 and L-PBF2 independent of the direction of feed motion of the end mill relative to the build-up direction of the workpiece (parallel or perpendicular). We believe that the difference in the chip form is for the following two reasons: differences in the microstructure and the chemical composition of the materials. The micrographs of the materials in Figs. 5 and 7 reveal a larger grain size for the reference material and a significantly more inhomogeneous microstructure. The larger grains lead to a lower hardness. A smaller yield strength and ultimate tensile strength are therefore expected for the reference material following Keist et al. [39] who reported a linear correlation between the microhardness and the two mentioned mechanical properties. It can hence be assumed that the reference material can only withstand smaller stresses than the L-PBF materials, and thus, the chips break earlier. The inhomogeneous microstructure of the reference material usually results in high stresses near the silicon particles during the chip flow. These high stresses facilitate the initiation and propagation of cracks [40], which lead to the chip breakage. The silicon content in the reference material is approximately $6 \%$ higher as the silicon content in the L-PBF materials. A larger silicon content improves the chip breakage as the material becomes more brittle [41]. The combination of the larger grain size, the more inhomogeneous microstructure, and the higher silicon content might be the reason for the earlier chip breakage of the reference material.

Figure 9 illustrates exemplary SEM images, which are representative for the respectively generated chips. An almost uniformly deformed material structure is apparent at each chip, except for the free surfaces of the chips. These exhibit a lamella structure which is typical for most metallic materials 


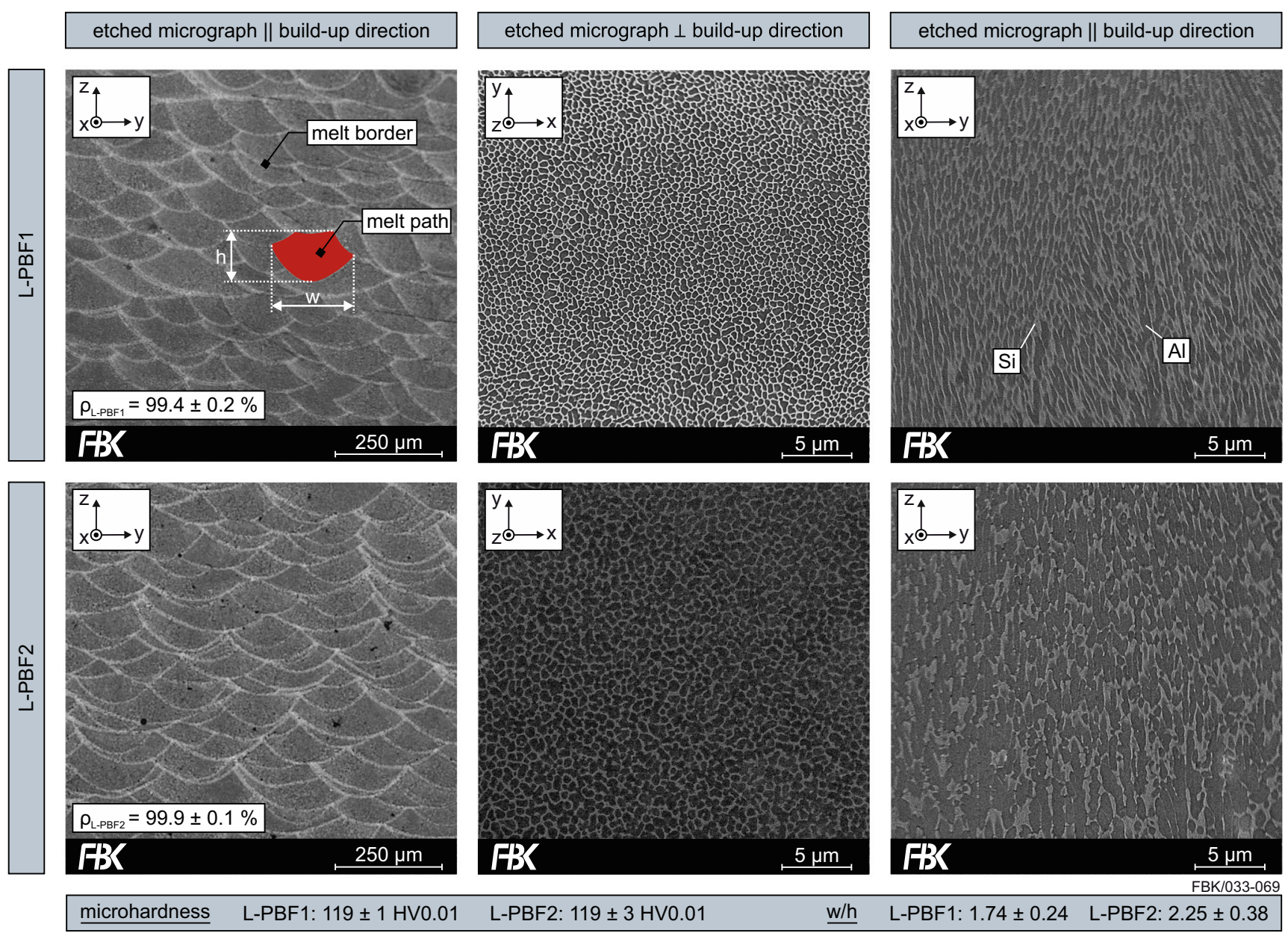

Fig. 5 Microstructure (left images: Kroll etching agent; rest: Keller etching agent), microhardness, and ratio of melt path width $w$ to melt path height $h$ of the L-PBF1 and L-PBF2 specimens

[38]. The almost uniformly deformed material structure is characteristic for a continuous chip formation. This mechanism of chip formation allows for two conclusions. The degree of deformation in the shear zones is lower than the respective shear strength of the materials. The microstructure of the materials is homogeneous enough to enable a
Fig. 6 Etched (Kroll etching agent) micrographs of L-PBF2: contour and bulk microstructure

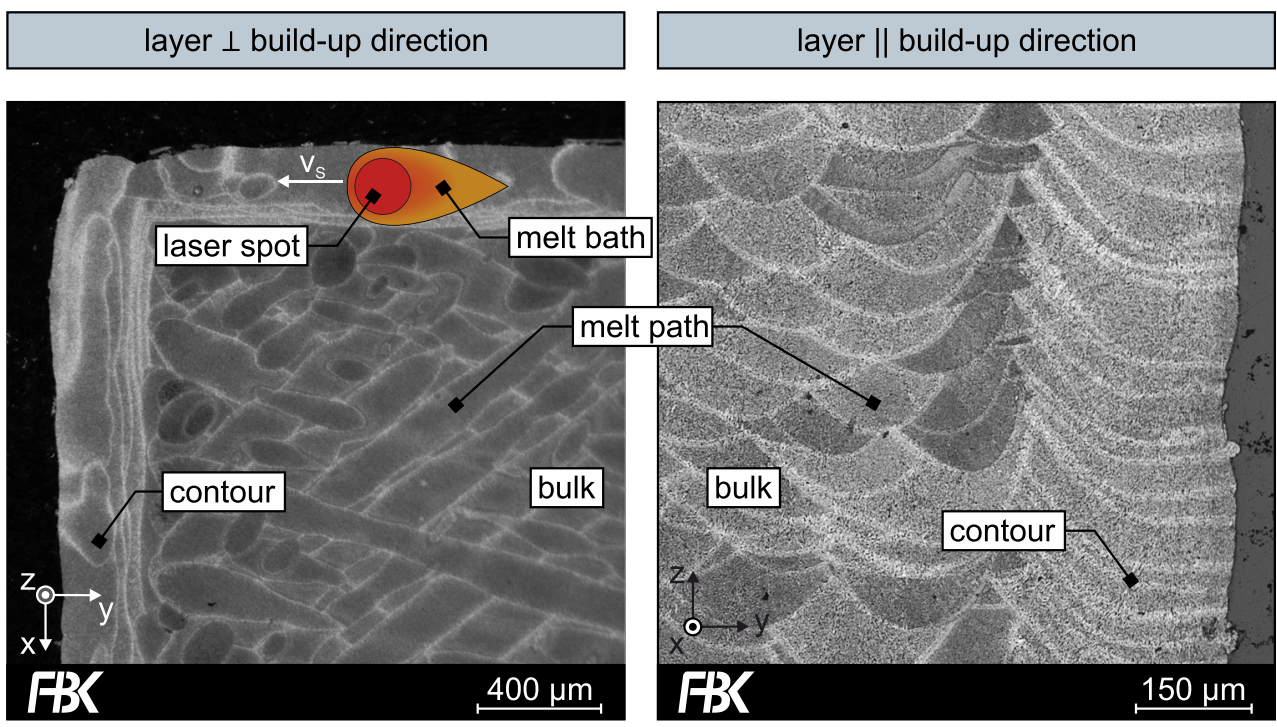

FBK/033-066 


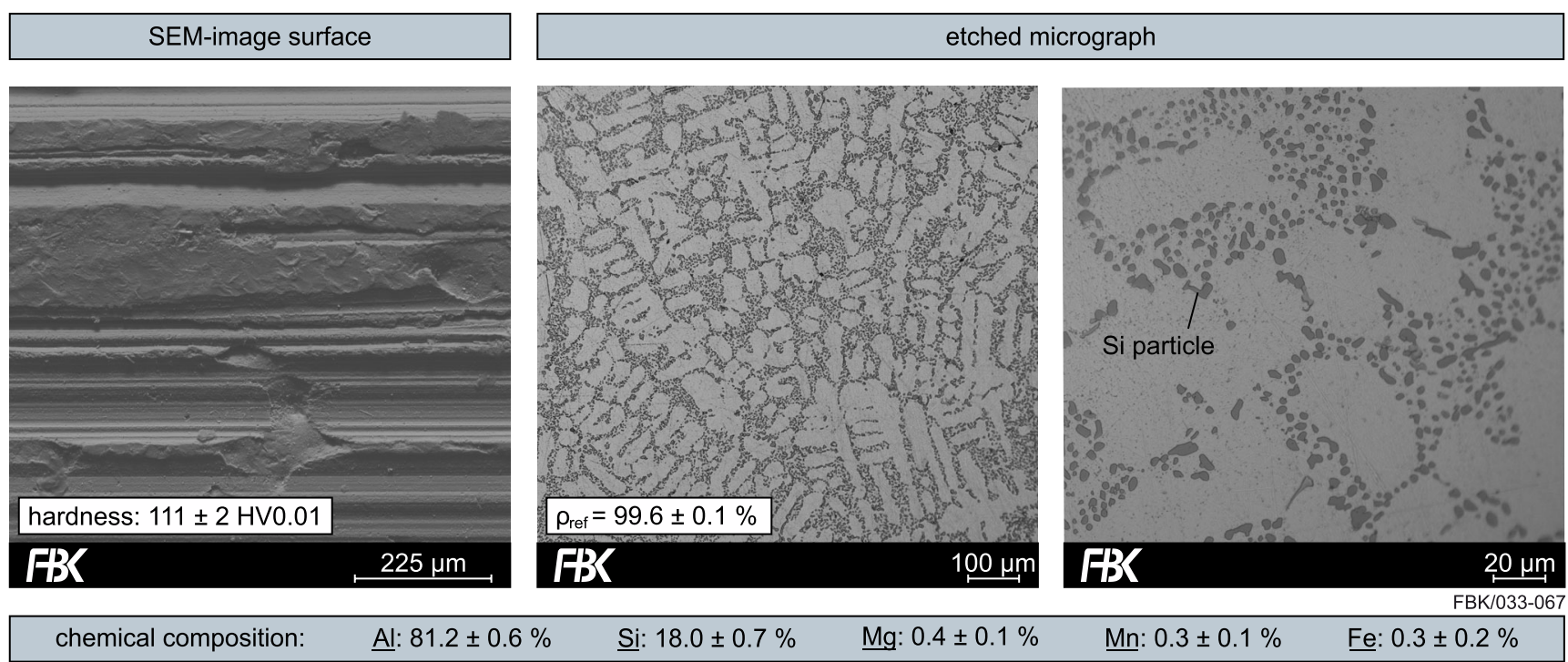

Fig. 7 Reference material: as-cast surface, hardness, etched (Keller etching agent) micrographs, relative density, and chemical composition

continuous chip formation with an almost uniform degree of deformation along the chip length and chip width. Within our investigations, L-PBF did not influence the chip morphology in comparison to the reference manufacturing method.

\subsection{Process forces}

The resultant forces during milling of L-PBF1, L-PBF2, and the reference workpieces are shown in Fig. 10.
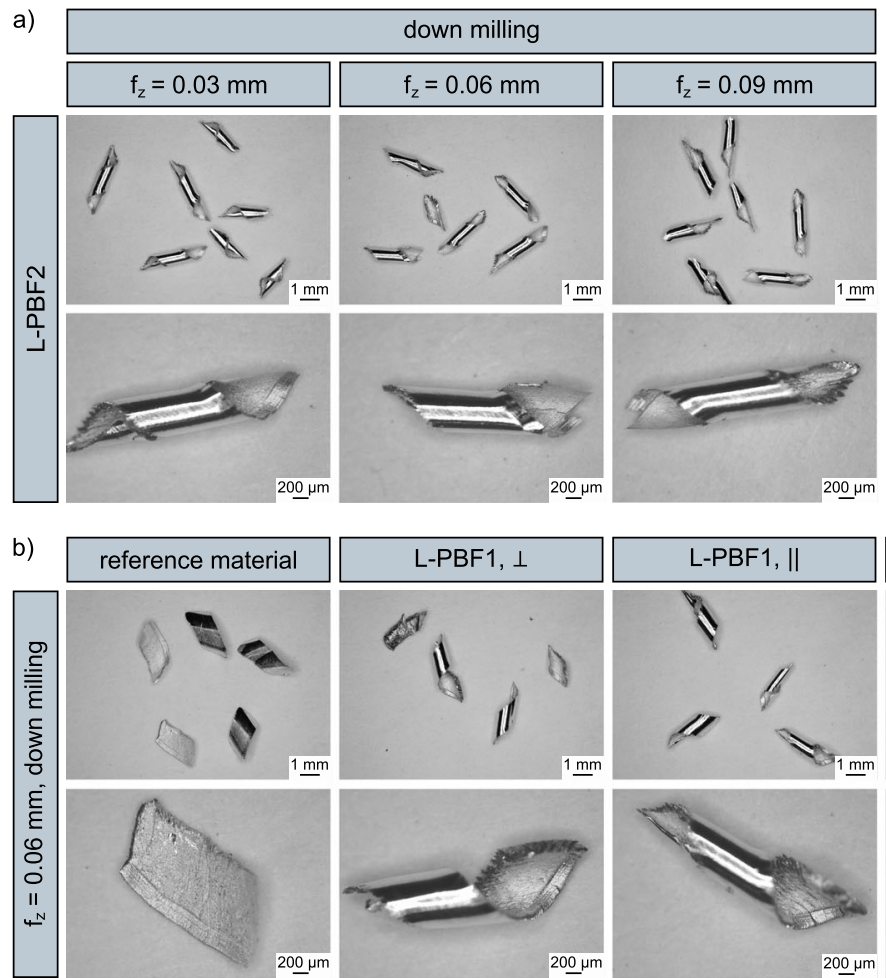

An increase of the feed per tooth leads to higher resultant forces due to the associated rise of the undeformed chip thickness. As a result of the larger undeformed chip thickness, more material is removed during a single rotation of the end mill, resulting in a larger energy requirement for the plastic deformation of the material and the overcoming of the higher friction [42]. In addition, a tendency towards larger resultant forces was found during up milling compared to down milling. This is a common observation, which can be attributed to
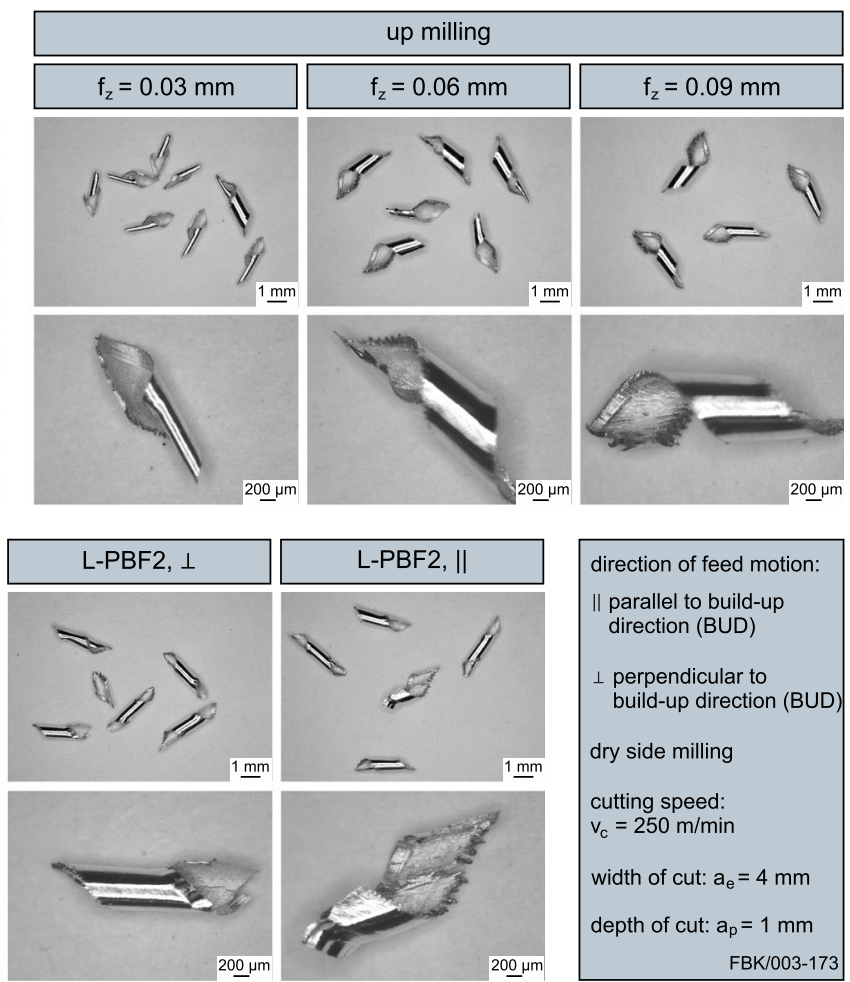

Fig. 8 Chip forms in dependence on (a) the cutting condition when milling the L-PBF2 specimens perpendicular to the BUD and (b) on the manufacturing method of the workpieces at the same cutting condition for milling 


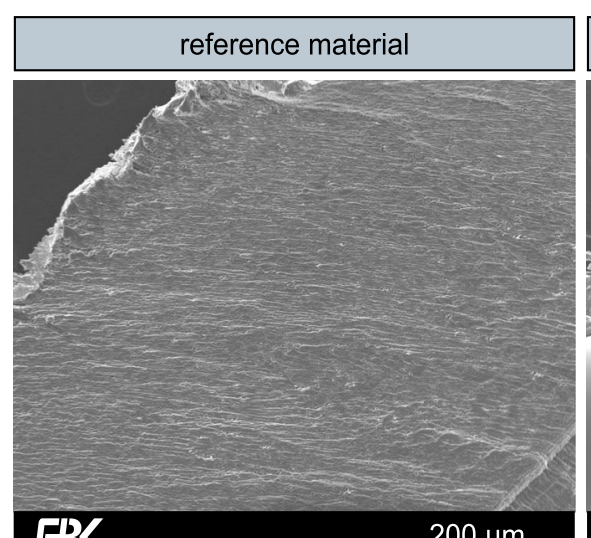

FBK

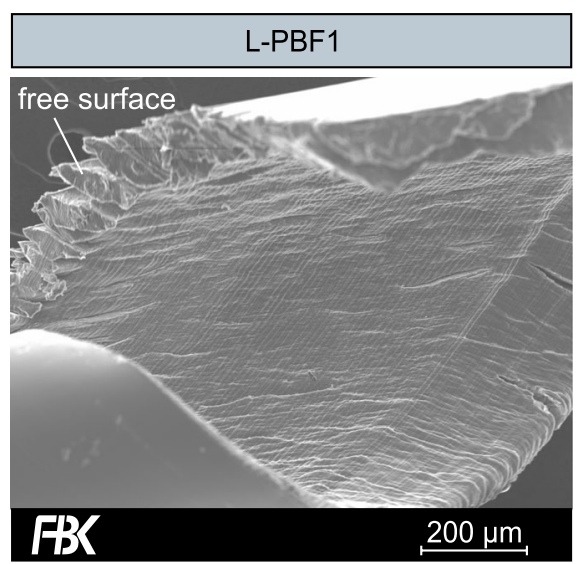

$200 \mu \mathrm{m}$

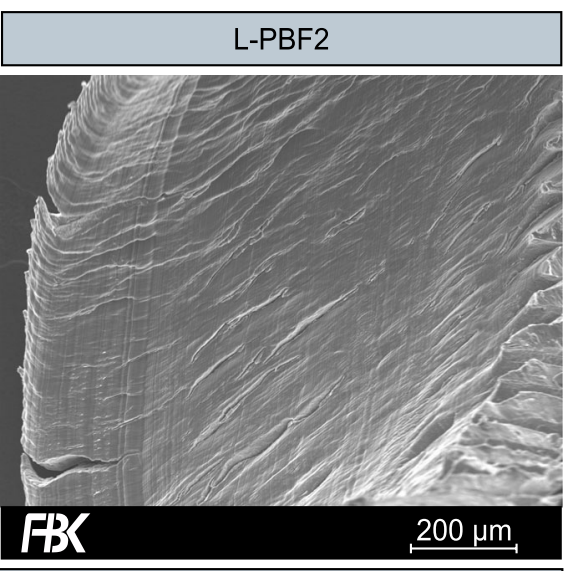

up milling

FBK/003-174 width of cut: $a_{e}=4 \mathrm{~mm}$ cutting speed: $v_{c}=250 \mathrm{~m} / \mathrm{min}$ depth of cut: $a_{p}=1 \mathrm{~mm}$ feed per tooth: $f_{z}=0.06 \mathrm{~mm}$

Fig. 9 Chip morphology of differently manufactured AlSi10Mg

the more pronounced plowing of the material and the higher friction during up milling.

Regarding L-PBF2, the magnitude of the forces depends strongly on the direction of feed motion of the end mill relative to the build-up direction of the workpieces. Significantly higher forces (17.3-39.1\%) were observed when milling parallel to the BUD. The smaller the feed per tooth, the higher the percentage difference. Up milling causes larger differences in the resultant forces between the two examined directions of tool feed motion than down milling. During up milling, the differences in the resultant forces range from 18.7 to $39.1 \%$. This difference decreases to $17.3-28.9 \%$ when down milling. For L-PBF1, there is no significant effect of the direction of feed motion of the end mill on the forces.

The increased force when milling with $\mathrm{v}_{\text {fll }}$ can be attributed to the anisotropic microstructure, which is characteristic for workpieces produced via L-PBF. According to Hall [43], there is an accumulation of dislocations at grain boundaries, which may be comparable to melt borders (Fig. 5). During milling, dislocations are moved through the material until they reach the next melt border. Due to the accumulation and hence increased number of dislocations at melt borders, their freedom of movement is reduced, which results in a local material strengthening. In addition, L-PBF results in very high cooling rates $\left(10^{3}-10^{8} \mathrm{~K} / \mathrm{s}\right.$ [12]) of the melt, such as those used in laser transformation hardening processes, which utilize the rapid solidification to modify surface properties [44]. Due to the comparatively low density of the surrounding powder bed [45], most of the heat is dissipated into the already built component below, which acts as heat sink. The temperature distribution of the melt is inhomogeneous: the melt's temperature decreases from the inside to the outside [46]; therefore, the
Fig. 10 Resultant forces for different manufacturing methods of the specimens, cutting conditions, and directions of feed motion of the tool relative to the build-up direction of the workpiece

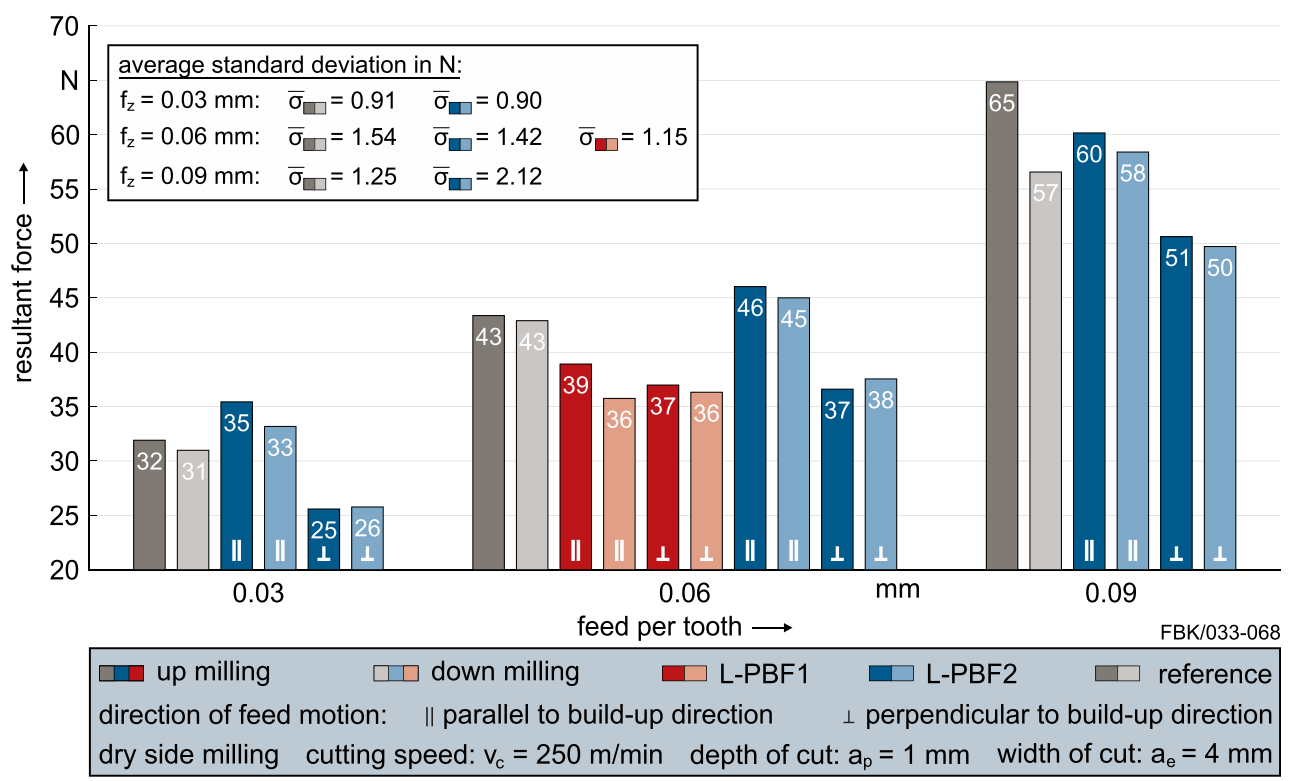


outer regions of the melt solidify first. Due to this, the first material to solidify is the melt border, which could lead to the segregation of alloying elements in this region. As a result, crossing the melt borders during milling temporarily increases the forces due to the locally increased material strength and possible segregations. When milling with $\mathrm{v}_{\mathrm{fl}}$, significantly more melt borders are crossed than when milling with $\mathrm{v}_{\mathrm{f}_{\perp}}$, as the ratio of melt path width to melt path height of LPBF2 is $2.25 \pm 0.38$. L-PBF1 applies $\mathrm{w} / \mathrm{h}=1.74 \pm 0.24$, which is closer to 1 and therefore corresponds to a much more balanced ratio of melt path width to melt path height. Due to this ratio, the number of crossed melt borders when milling LPBF1 is less dependent on the direction of feed motion, which in turn leads to almost identical resultant forces in both examined directions. The ratio of melt path width to melt path height $\mathrm{w} / \mathrm{h}$ and the direction of feed motion of the tool relative to the BUD are a measure for the number of melt borders to be crossed during subtractive manufacturing. This number has a significant influence on the resultant forces. A larger number of melt borders to be crossed increased the forces.

The size ratio of the forces when milling the differently manufactured workpieces (L-PBF1, L-PBF2, reference) depends on the direction of feed motion of the end mill relative to the build-up direction of the workpieces. Parallel to the BUD, the maximum forces were observed when milling LPBF2, while the minimum forces occurred for L-PBF1. Milling perpendicular to the BUD results in roughly the same forces for L-PBF1 and L-PBF2. These forces are smaller than the forces when milling the reference.

Taking only the hardness of the differently manufactured AlSi10Mg into account, higher forces could have been expected for the L-PBF materials, as the hardness is higher compared to that of the reference. However, other researchers revealed a considerable effect of the microstructure of a material on the forces during machining. Approximately the same or even higher forces have been reported for a coarser microstructure despite the lower hardness compared to the same material with a finer microstructure $[47,48]$. This agrees well with our investigations. The microstructure of the reference material is coarser than the microstructure of the L-PBF material. Due to this, the ductility of the reference material is higher. Materials with a higher ductility usually exhibit a higher degree of plastic deformation during chip formation [47]. The milling of the reference material could thus require more energy for the plastic deformation of the material during chip formation yielding into higher resultant forces, except for the milling of L-PBF2 parallel to the build-up direction.

\subsection{Surface morphology}

The roughness of the milled surfaces is depicted in Fig. 11 in dependence on the feed per tooth and the kinematic (up milling or down milling) used for milling, the manufacturing method of the AlSi10Mg, and the direction of feed motion of the tool relative to the build-up direction of the workpieces. At the lowest feed per tooth considered, the roughness of the milled L-PBF2 workpieces is slightly less than the roughness of the milled reference workpieces. This ratio of the surface roughness values changes with a rise of feed per tooth, except for two conditions. The surfaces of the reference workpieces are smoother than those of the L-PBF1 and L-PBF2 workpieces if higher feeds per tooth and thus larger undeformed chip thicknesses are used for milling. Up milling tends to cause higher $\mathrm{Ra}$ than down milling both for the reference and L-PBF material. The differences in the roughness between up milling and down milling, however, are sometimes small. It is likely that the larger roughness values of the up milled surfaces are due to the stronger squeezing of the material [49].

The direction of feed motion of the tool relative to the BUD significantly influences the surface roughness only for LPBF2. Milling perpendicular to the build-up direction is accompanied with a higher arithmetic mean roughness, particularly at the larger feeds per tooth examined. Such a distinct trend could not be observed for L-PBF1. The comparison of $\mathrm{Ra}$ reveals that the surfaces of the L-PBF2 workpieces are much smoother than those of the L-PBF1 workpieces when milling parallel to the BUD. This ratio is reversed for a direction of the feed motion perpendicular to the build-up direction. In this case, the roughness of the milled L-PBF2 workpieces is slightly higher.

SEM images of the up milled surfaces are shown in Fig. 12. D-marks are present on each surface. They depict the peak of the kinematic roughness and result from the cycloidal movement of the cutting edge (due to linear feed motion and simultaneous rotation) through the material during a tool engagement. The higher the feed per tooth, the larger the kinematic roughness. There are differences in the surface structure between the milled L-PBF workpieces and the reference workpieces. In the milled surfaces of the reference, multiple silicon grains protrude from the surface, and smeared material is visible on the surface. These irregularities increase the roughness depending on their size. The surfaces of the milled L-PBF workpieces show a severe flaky structure with clearly visible flake fragments protruding from the surface. In the case of LPBF2, the intensity of this flake formation and the surface structure strongly depends on the direction of feed motion of the tool relative to the build-up direction. In milling with a direction of feed motion perpendicular to the BUD of the workpieces, the flake formation is much more pronounced than in milling parallel to the BUD. As a result, the surface roughness is also higher in this direction of feed motion (Fig. 11). Such a considerable difference in the surface structure is not present at the milled L-PBF1 workpieces. Debris of AlSi10Mg are apparent on the surfaces of the milled L-PBF workpieces. These debris are presumably flakes that were completely pulled out of the surface. The flaky structure of 
Fig. 11 Surface roughness in dependence on the manufacturing method of the material and the cutting condition used for milling

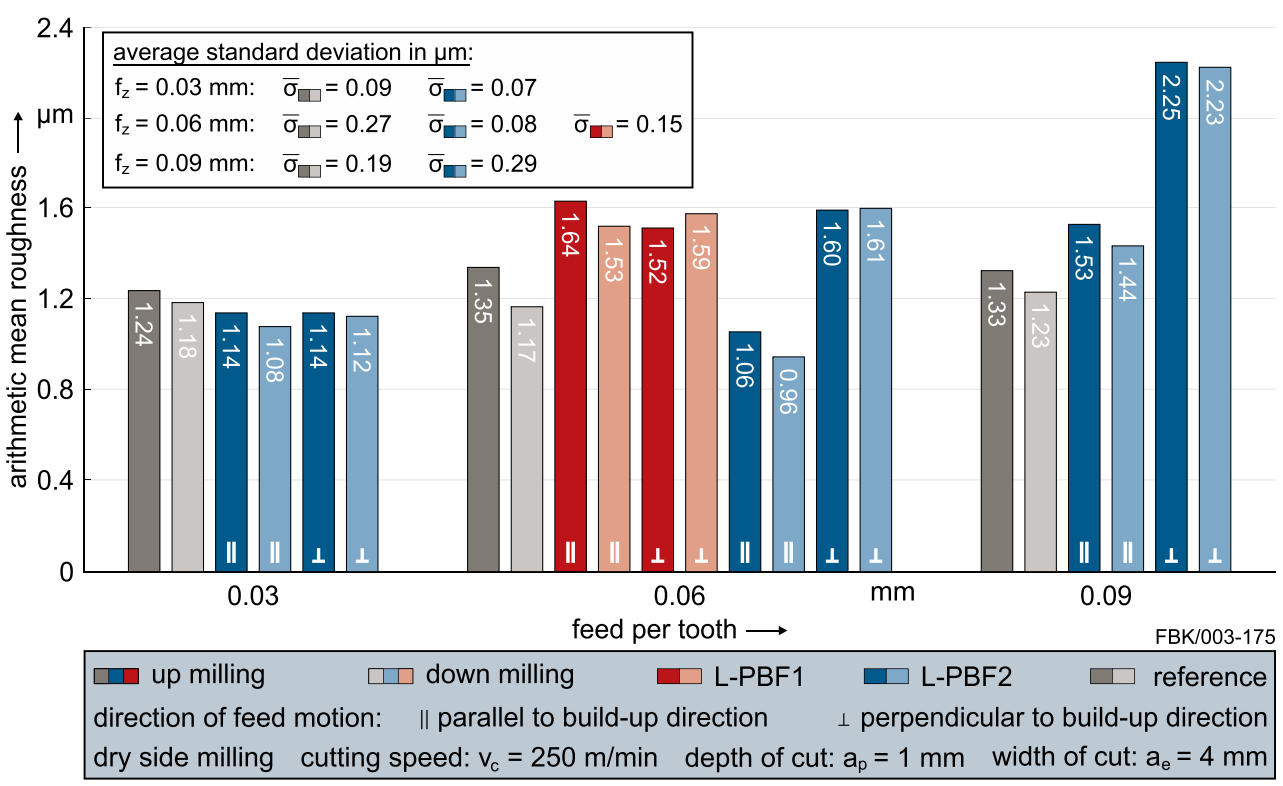

the surface and the debris on the surface increase the roughness, as both the magnitude of the peaks and the valleys (due to the pull-out of the material) of the surface profile are enlarged.

In Fig. 13, the microhardness depth profiles of the LPBF1, L-PBF2, and reference workpieces are depicted in dependence on the feed per tooth used for milling. The microhardness depth profiles show similar results for each manufacturing method of the material and feed per tooth used. All values are in the range of 107126 HV0.01. The hardness does not significantly change for distances from the workpiece surface from 25 to $280 \mu \mathrm{m}$. The thermo-mechanical loads on the material during milling therefore did not lead to a change in the microstructure and thus the microhardness of the material. Higher loads could have caused such a change.

\subsection{Burrs}

The burr formation differs between the reference material and the L-PBF materials (Fig. 14). Regardless of the feed per tooth, the milling kinematics, and the feed direction of the end mill relative to the build-up direction of the workpieces, no burrs (Fig. 14b and c) can be detected on the L-PBF1 and L-PBF2 workpieces, while burrs occurred when milling the reference material.

While no burrs could be detected when milling the reference material in down milling mode (Fig. 14a) and no entrance burrs can be found when up milling (Fig. 14a and c), entrance side burrs (rollover burr), top burrs, exit side burrs (rollover burrs), and exit burrs were always formed when up milling, irrespective of $f_{z}$. The feed per tooth does not significantly affect the size of the burrs.
The differences in burr formation in up milling and down milling of the reference material could be attributed to a higher friction and stronger squeezing of the material in up milling. This is caused by not achieving the minimum chip thickness at the tooth entrance until a certain feed motion angle is reached. The higher process temperatures during up milling could also facilitate the burr formation, as the material gets more ductile at elevated temperatures [49].

The different manufacture of the contour and the bulk could be the reason for the absence of burrs. In order to investigate this, the contour layer at as-built workpieces was removed by milling. Using these identically pre-milled workpieces, additional milling tests were carried out using a feed per tooth of $0.06 \mathrm{~mm}$ (Fig. 15). These tests allow for two conclusions. First, the different orientation of the melt paths of the contour compared to the workpiece's bulk (Fig. 6) does not explain the absence of burrs on the L-PBF workpieces. No burrs were formed on these pre-milled workpieces either. Second, the irregularities on the as-built surfaces of the L-PBF workpieces do not affect the burr formation.

Bonati et al. [50] as well as Hojati et al. [47] observed that when micro milling parts made of Ti6Al4V, the additively manufactured (laser-engineered net shaping (LENS), respectively; electron beam melting (EBM)) parts showed significantly more burr formation than the extruded parts despite their higher hardness. Hojati et al. [47] concluded, in agreement with Lizzul et al. [51] as well as Khaliq et al. [52], that other factors related to the microstructure of the material may have an essential role in burr formation. Our reference material exhibits a significantly coarser microstructure than the L-PBF AlSi10Mg (Fig. 5 and Fig. 7). A coarser microstructure 


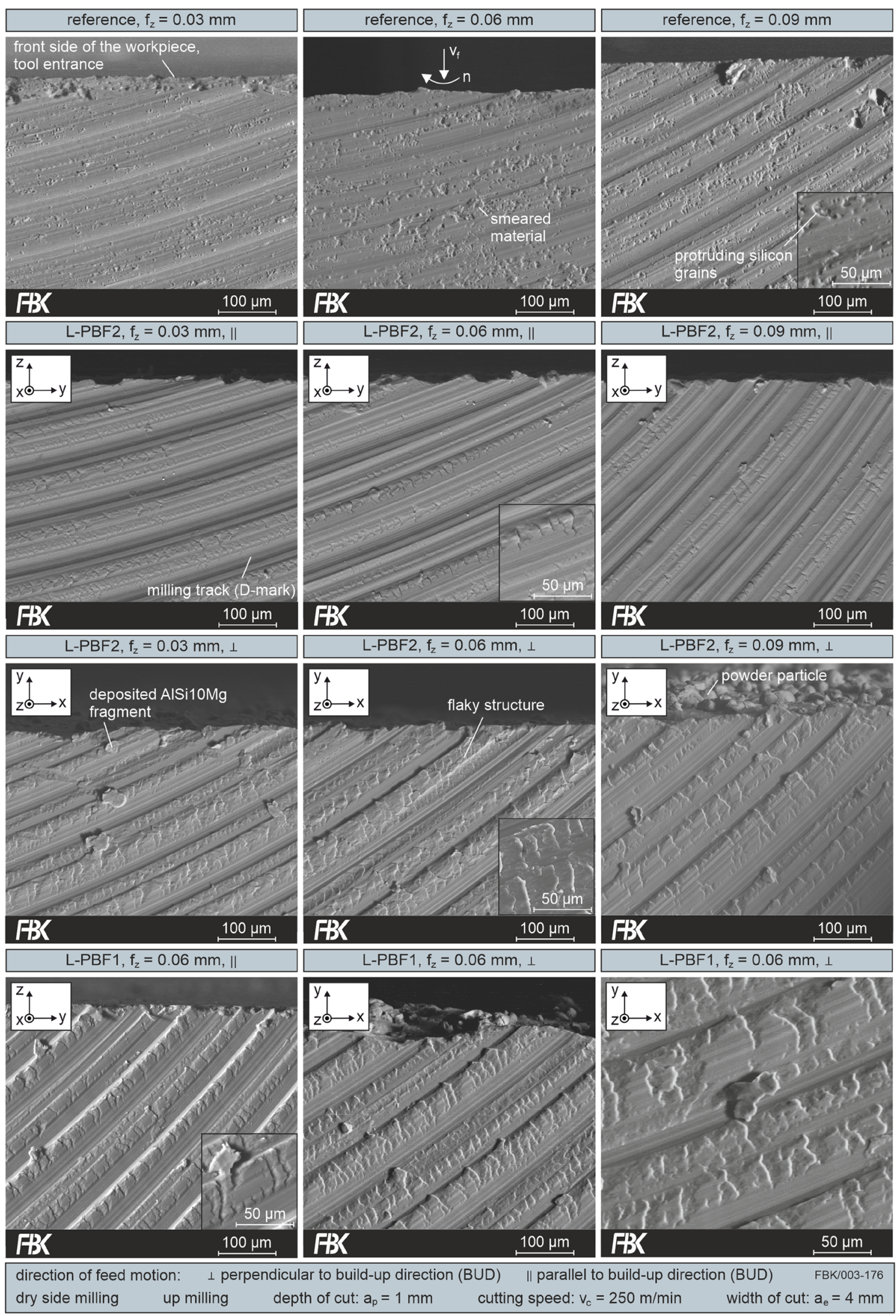

Fig. 12 SEM images of the up milled workpiece surfaces 
is accompanied with a higher ductility and thus a larger possible plastic deformation of the material during machining [47], as larger grains facilitate the dislocation movement [53] on which the plastic deformation of metals is based. In general, the amount of plastic deformation of the material in the cutting zone is the decisive factor for the burr formation. A more intense dislocation movement and thus a greater plastic deformation favors burr formation [47, 53]. The dislocation movement in the reference material is more pronounced in comparison to the L-PBF material due to its coarser microstructure. This could explain the greater tendency of the reference material to form burrs. The fine-grained microstructure of the L-PBF material impeded the dislocation movement. Therefore, presumably no burrs were formed.

\section{Conclusions and outlook}

The machinability of laser-based powder bed-fused AlSi10Mg was explored in this study in dependence on the manufacturing parameter settings used for L-PBF and the direction of feed motion of the end mill relative to the build-up direction of the workpiece. The results were compared with a cast and heat-treated (T6) AlSi10Mg reference material. The following conclusions can be drawn from the investigations:
- Continuous chips were formed regardless of the manufacturing method of the material and the cutting condition used for milling. The unique microstructure of materials manufactured using L-PBF thus did not influence the mechanism of chip formation in comparison to the reference. However, the chip form varied. Milling the reference material resulted in discontinuous chips. The chips observed when milling the additively manufactured aluminum alloy can be classified as spiral chip segments.

- The ratio of the melt path width to the melt path height and the direction of feed motion of the end mill relative to the build-up direction are a measure for the number of melt borders to be crossed when milling. A larger number of melt borders to be crossed significantly increased the resultant forces. Milling of the reference material mainly resulted in higher forces compared to the L-PBF AlSi10Mg despite the $7 \%$ lower hardness of the reference. The exceptions were higher forces when milling the LPBF material at the maximum number of melt borders to be crossed. The all in all higher forces might be due to the significantly coarser microstructure of the reference, which could lead to a higher degree of plastic deformation of the material during cutting.

- The manufacturing method of the AlSi10Mg influences the surface roughness and surface structure of the milled
Fig. 13 Microhardness depth profiles for L-PBF1, L-PBF2, and reference workpieces

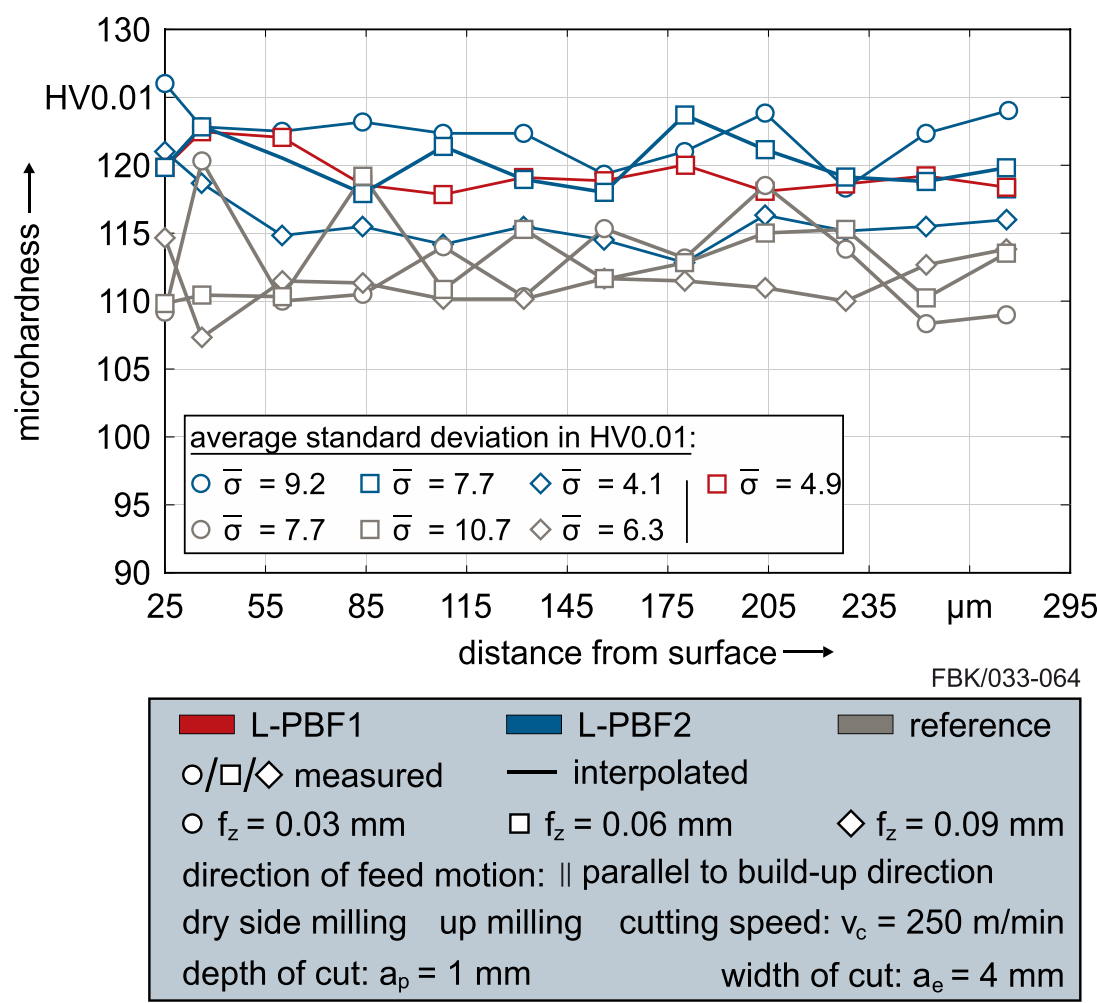



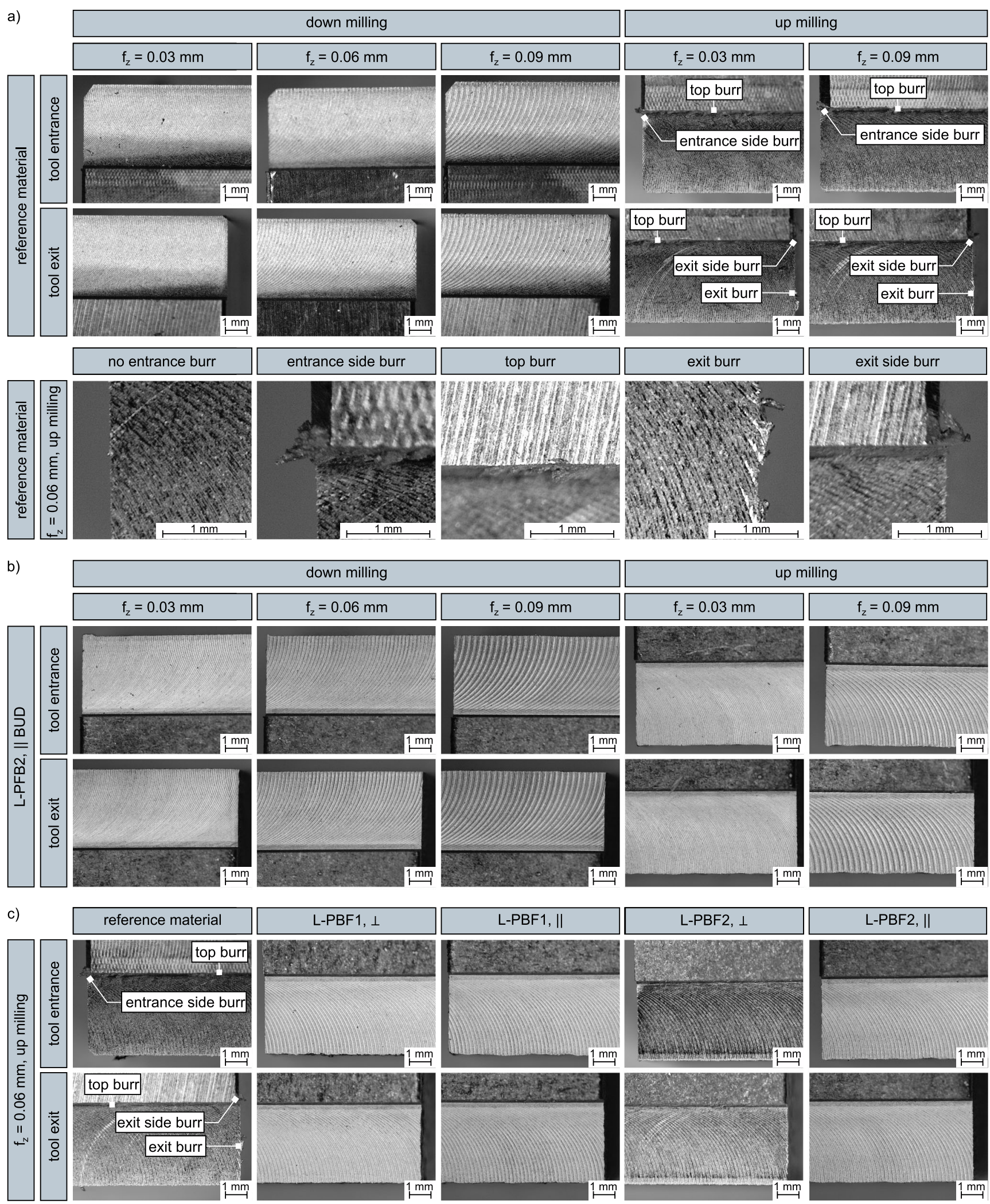

direction of feed motion: $\|$ parallel to build-up direction (BUD) $\perp$ perpendicular to build-up direction (BUD)

dry side milling cutting speed: $v_{c}=250 \mathrm{~m} / \mathrm{min} \quad$ width of cut: $a_{e}=4 \mathrm{~mm} \quad$ depth of cut: $a_{p}=1 \mathrm{~mm}$

Fig. 14 Workpiece edges in dependence on (a) the feed per tooth and kinematic used to mill the reference material, (b) the feed per tooth and kinematic used to mill the L-PBF2 material, and (c) the manufacturing method of the material, and the feed direction of the end mill relative to the build-up direction of the workpieces 


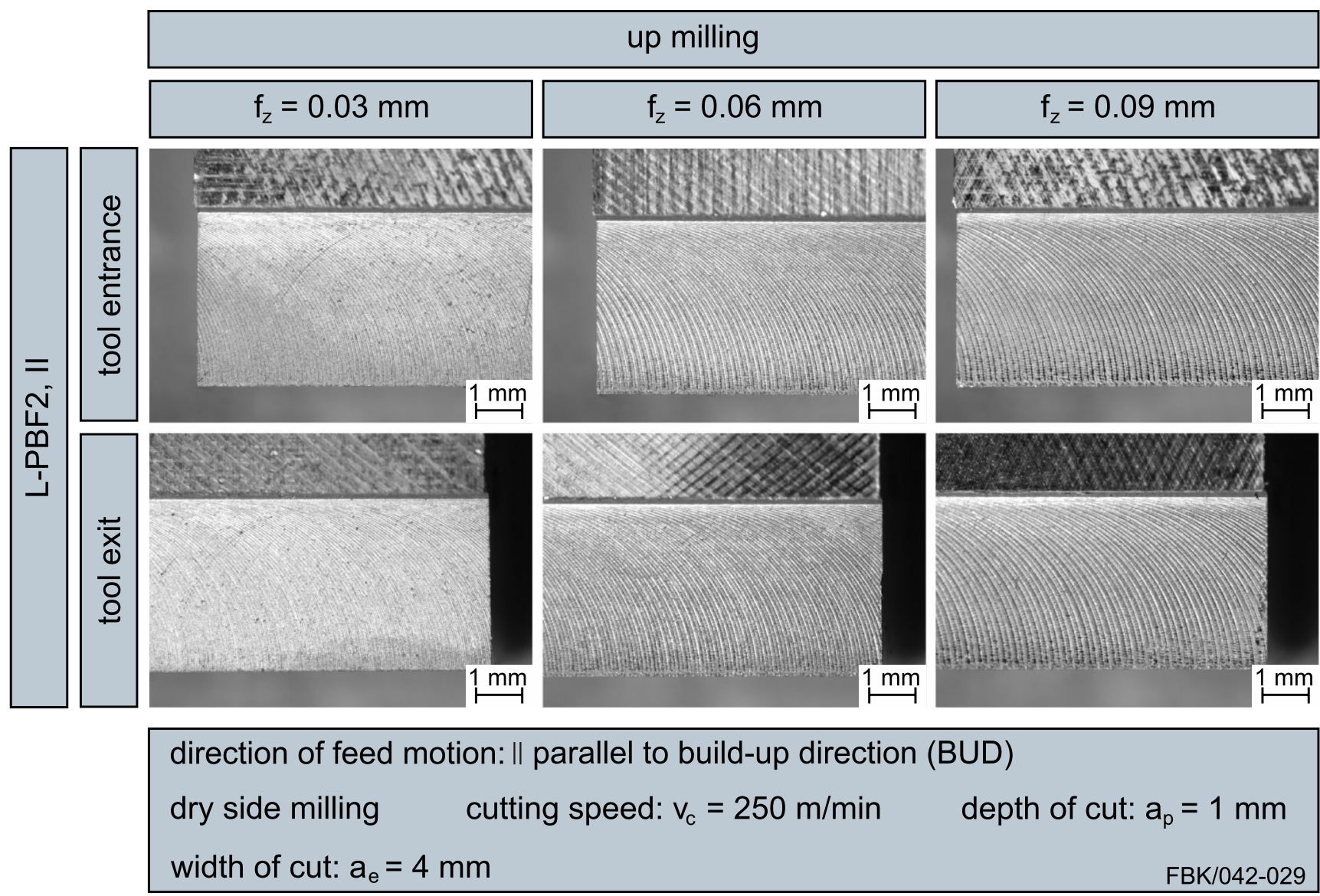

Fig. 15 Workpiece edges of the milled L-PBF2 workpieces in dependence on the feed per tooth; the contour layer on the as-built workpieces was removed before the milling tests

workpieces. In most cases, the surfaces of the milled reference workpieces were smoother than the surfaces of the material manufactured using L-PBF. This is due to the different structures of the milled surfaces. The surfaces of the L-PBF materials show a severe flaky structure with clearly visible flake fragments protruding from the surface. Such flakes were not observed on the surfaces of the milled reference material. The number of melt borders to be crossed is an important factor for the quality of the milled surfaces. Considering the material produced with a layer thickness of $60 \mu \mathrm{m}$, the roughness and structure of the surfaces did not depend on the direction of feed motion of the tool relative to the build-up direction of the workpieces. In the case of the layer thickness of $30 \mu \mathrm{m}$, the flake formation is much more pronounced in milling with a direction of feed motion of the tool perpendicular to the build-up direction than in milling parallel to the build-up direction. As a result, the surface roughness is also higher in this direction of feed motion.

- Milling the additively manufactured workpieces did not lead to the formation of burrs regardless of the manufacturing parameter setting applied for L-PBF and the cutting condition used. However, entrance side burrs, top burrs, exit side burrs, and exit burrs were found when up milling the reference material. We believe that the significant differences in the microstructure of the materials could be the reason for the observed differences in burr formation.

In future work, the mechanisms of surface generation when milling AlSi10Mg manufactured via laser-based powder bed fusion will be investigated in more detail in order to understand the resulting surface in-depth. Moreover, the behavior of the L-PBF material at the tool entrance and tool exit will be explored more comprehensively. This could enable a reproducible high-quality finishing of L-PBF workpieces via machining.

Authors' contributions Not applicable.

Funding Open Access funding enabled and organized by Projekt DEAL. This research was funded by the State Research focus "Advanced Materials Engineering (AME)" at the Technische Universität Kaiserslautern. The authors also received support from the KSB Stiftung for the research project 1.1352.2019.1 "OptiAM - Gestaltung additiv subtraktiver Prozessketten der Fertigung." 
Data Availability Not applicable.

\section{Compliance with ethical standards}

Competing interests The authors declare that they have no competing interests.

Ethics approval Not applicable.

Consent to participate Not applicable.

Consent for publication Not applicable.

Code availability Not applicable.

Open Access This article is licensed under a Creative Commons Attribution 4.0 International License, which permits use, sharing, adaptation, distribution and reproduction in any medium or format, as long as you give appropriate credit to the original author(s) and the source, provide a link to the Creative Commons licence, and indicate if changes were made. The images or other third party material in this article are included in the article's Creative Commons licence, unless indicated otherwise in a credit line to the material. If material is not included in the article's Creative Commons licence and your intended use is not permitted by statutory regulation or exceeds the permitted use, you will need to obtain permission directly from the copyright holder. To view a copy of this licence, visit http://creativecommons.org/licenses/by/4.0/.

\section{References}

1. Galy C, Le Guen E, Lacoste E, Arvieu C (2018) Main defects observed in aluminum alloy parts produced by SLM: from causes to consequences. Addit Manuf 22:165-175. https://doi.org/10. 1016/j.addma.2018.05.005

2. Koutiri I, Pessard E, Peyre P, Amlou O, De Terris T (2018) Influence of SLM process parameters on the surface finish, porosity rate and fatigue behavior of as-built Inconel 625 parts. J Mater Process Technol 255:536-546. https://doi.org/10.1016/j. jmatprotec.2017.12.043

3. Buchbinder D, Schleifenbaum H, Heidrich S, Meiners W, Bültmann J (2011) High power selective laser melting (HP SLM) of aluminum parts. Phys Procedia 12:271-278. https://doi.org/10. 1016/j.phpro.2011.03.035

4. Olleak A, Xi Z (2020) A scan-wise adaptive remeshing framework for thermal simulation of the selective laser melting process. Int $\mathrm{J}$ Adv Manuf Technol 107:573-584. https://doi.org/10.1007/s00170020-04995-7

5. Zhang B, Coddet C (2016) Selective laser melting of iron powder: observation of melting mechanism and densification behavior via point-track-surface-part research. J Manuf Sci Eng 138:051001. https://doi.org/10.1115/1.4031366

6. Cheng B, Shrestha S, Chou K (2016) Stress and deformation evaluations of scanning strategy effect in selective laser melting. Addit Manuf 12:240-251. https://doi.org/10.1016/j.addma.2016.05.007

7. Blinn B, Ley M, Buschhorn N, Teutsch R, Beck T (2020) Investigation of the anisotropic fatigue behavior of additively manufactured structures made of AISI 316L with short-time procedures PhyBaLLIT and PhyBaLCHT. Int J Fatigue 124:389-399. https://doi.org/10.1016/j.ijfatigue.2019.03.022

8. Zhou X, Dai N, Chu M, Wang L, Li D, Zhou L, Cheng X (2020) Xray $\mathrm{CT}$ analysis of the influence of process on defect in Ti-6Al-4V parts produced with selective laser melting technology. Int J Adv Manuf Technol 106:3-14. https://doi.org/10.1007/s00170-01904347-0

9. Majeed A, Ahmed A, Salam A, Sheikh MZ (2019) Surface quality improvement by parameters analysis, optimization and heat treatment of AlSi10Mg parts manufactured by SLM additive manufacturing. Int J Lightweight Mater Manuf 2:288-295. https:// doi.org/10.1016/j.ijlmm.2019.08.001

10. Blinn B, Klein M, Gläßner C, Smaga M, Aurich JC, Beck T (2018) An investigation of the microstructure and fatigue behavior of additively manufactured AISI $316 \mathrm{~L}$ stainless steel with regard to the influence of heat treatment. Metals 8:220. https://doi.org/10.3390/ met 8040220

11. Ahmed A, Majeed A, Atta Z, Jia G (2019) Dimensional quality and distortion analysis of thin-walled alloy parts of AlSil0Mg manufactured by selective laser melting. J Manuf Mater Process 3:51. https://doi.org/10.3390/jmmp3020051

12. Zhang J, Song B, Wei Q, Bourell D, Shi Y (2019) A review of selective laser melting of aluminum alloys: processing, microstructure, property and developing trends. J Mater Sci Technol 35:270 284. https://doi.org/10.1016/j.jmst.2018.09.004

13. Milton S, Morandeaua A, Chalonb F, Leroy R (2016) Influence of finish machining on the surface integrity of Ti6Al4V produced by selective laser melting. Procedia CIRP 45:127-130. https://doi.org/ 10.1016/j.procir.2016.02.340

14. Leon A, Aghion E (2017) Effect of surface roughness on corrosion fatigue performance of AlSi10Mg alloy produced by selective laser melting (SLM). Mater Charact 131:188-194. https://doi.org/10. 1016/j.matchar.2017.06.029

15. Vayssette B, Saintier N, Brugger C, Elmay M, Pessard E (2018) Surface roughness of Ti-6Al-4V parts obtained by SLM and EBM: effect on the high cycle fatigue life. Procedia Eng 213:89-97. https://doi.org/10.1016/j.proeng.2018.02.010

16. Delgado J, Ciurana J, Rodríguez CA (2012) Influence of process parameters on part quality and mechanical properties for DMLS and SLM with iron-based materials. Int J Adv Manuf Technol 60: 601-610. https://doi.org/10.1007/s00170-011-3643-5

17. Brinksmeier E, Levy G, Meyer D, Spierings AB (2010) Surface integrity of selective-laser melted components. CIRP Ann Manuf Technol 59:601-606. https://doi.org/10.1016/j.cirp.2010.03.131

18. Flynn JM, Shokrani A, Newman ST, Dhokia V (2016) Hybrid additive and subtractive machine tools - research and industrial developments. Int J Mach Tools Manuf 101:79-101. https://doi. org/10.1016/j.ijmachtools.2015.11.007

19. Kaynaka Y, Kitay O (2019) The effect of post-processing operations on surface characteristics of $316 \mathrm{~L}$ stainless steel produced by selective laser melting. Addit Manuf 26:84-93. https://doi.org/10. 1016/j.addma.2018.12.021

20. Liu X, Zhao C, Zhou X, Shena Z, Liu W (2019) Microstructure of selective laser melted AlSi10Mg alloy. Mater Des 168:107677. https://doi.org/10.1016/j.matdes.2019.107677

21. Chen J, Hou W, Wang X, Chu S, Yang Z (2019) Microstructure, porosity and mechanical properties of selective laser melted AlSi10Mg. Chin J Aeronaut 33:2043-2054. https://doi.org/10. 1016/j.cja.2019.08.017

22. Bartlett JL, Croom BP, Burdick J, Henkel D, Li X (2018) Revealing mechanisms of residual stress development in additive manufacturing via digital image correlation. Addit Manuf 22:1-12. https://doi. org/10.1016/j.addma.2018.04.025

23. Song B, Dong S, Coddet P, Liao H, Coddet C (2014) Fabrication of $\mathrm{NiCr}$ alloy parts by selective laser melting: columnar microstructure and anisotropic mechanical behavior. Mater Des 53:1-7. https:// doi.org/10.1016/j.matdes.2013.07.010

24. Grove T, Denkena B, Maiß O, Krödel A, Schwab H, Kühn U (2018) Cutting mechanism and surface integrity in milling of Ti- 
5553 processed by selective laser melting. J Mech Sci Technol 32: 4883-4892. https://doi.org/10.1007/s12206-018-0936-8

25. Polishetty A, Shunmugavel M, Goldberg M, Littlefair G, Singh RK (2017) Cutting force and surface finish analysis of machining additive manufactured titanium alloy Ti-6Al-4V. Procedia Manuf 7: 284-289. https://doi.org/10.1016/j.promfg.2016.12.071

26. Le Coz G, Fischer M, Piquard R, D'Acunto A, Laheurte P, Dudzinski D (2017) Micro cutting of Ti-6Al-4V parts produced by SLM process. Procedia CIRP 58:228-232. https://doi.org/10. 1016/j.procir.2017.03.326

27. Sartori S, Moro L, Ghiotti A, Bruschi S (2017) On the tool wear mechanisms in dry and cryogenic turning additive manufactured titanium alloys. Tribol Int 105:264-273. https://oi.org/10.1016/j. triboint.2016.09.034

28. Alexeev VP, Balyakin AV, Khaimovich AI (2017) Influence of the direction of selective laser sintering on machinability of parts from 316L steel. IOP Conf Ser Mater Sci Eng 177:012120. https://doi. org/10.1088/1757-899X/177/1/012120

29. Liu Z, Li X, Wang X, Tian C, Wang L (2019) Comparative investigation on grindability of Inconel 718 made by selective laser melting (SLM) and casting. Int J Adv Manuf Technol 100:3155-3166. https://doi.org/10.1007/s00170-018-2850-8

30. Ullah R, Akmal JS, Laakso SVA, Niemi E (2020) Anisotropy of additively manufactured AlSi10Mg: threads and surface integrity. Int J Adv Manuf Technol 107:3645-3662. https://doi.org/10.1007/ s00170-020-05243-8

31. Struzikiewicz G, Zebala W, Slodki B (2019) Cutting parameters selection for sintered alloy AlSi10Mg longitudinal turning. Measurement 138:39-53. https://doi.org/10.1016/j.measurement. 2019.01.082

32. Read N, Wang W, Essa K, Attallah MM (2015) Selective laser melting of AlSi10Mg alloy: process optimisation and mechanical properties development. Mater Des 65:417-424. https://doi.org/10. 1016/j.matdes.2014.09.044

33. Li W, Li S, Liu J, Zhang A, Zhou Y, Wei Q, Yan C, Shi Y (2016) Effect of heat treatment on AlSi10Mg alloy fabricated by selective laser melting: microstructure evolution, mechanical properties and fracture mechanism. Mater Sci Eng A 663:116-125. https://doi.org/ 10.1016/j.msea.2016.03.088

34. Krishnan M, Atzeni E, Canali R, Calignano F, Manfredi D, Ambrosio EP, Iuliano L (2014) On the effect of process parameters on properties of AlSi10Mg parts produced by DMLS. Rapid Prototyp J 20(6):449-458. https://doi.org/10.1108/RPJ-03-20130028

35. DIN EN ISO 6507-1 (2018) Metallische Werkstoffe: Härteprüfung nach Vickers - Teil 1: Prüfverfahren, Beuth, Berlin. https://doi.org/ 10.31030/2778746

36. Yusuf SM, Chen Y, Boardman R, Yang S, Gao N (2017) Investigation on porosity and microhardness of $316 \mathrm{~L}$ stainless steel fabricated by selective laser melting. Metals 7(2):64. https://doi. org/10.3390/met7020064

37. Lofti M, Farid AA, Soleimanimehr H (2015) The effect of chip breaker geometry on chip shape, bending moment, and cutting force: FE analysis and experimental study. Int J Adv Manuf Technol 78:917-925. https://doi.org/10.1007/s00170-014-6676-8
38. Pacella M (2019) A new low-feed chip breaking tool and its effect on chip morphology. Int J Adv Manuf Technol 104:1145-1157. https://doi.org/10.1007/s00170-019-03961-2

39. Keist JS, Palmer TA (2017) Development of strength-hardness relationships in additively manufactured titanium alloys. Mater Sci Eng A 693:214-224. https://doi.org/10.1016/j.msea.2017.03.102

40. Lin JT, Bhattacharyya D, Ferguson WG (1998) Chip formation in the machining of SiC-particle-reinforced aluminium-matrix composites. Compos Sci Technol 58(2):285-291. https://doi.org/10. 1016/S0266-3538(97)00126-7

41. Stürenburg B (2009) Optimierung der Spanbildung und Minimierung des Späneeintrages in das Werkstück für das Bohren von Al-Legierungen. Dissertation, Technische Universität Kaiserslautern

42. Klocke F (2011) Manufacturing processes 1. Springer, Berlin

43. Hall EO (1951) The deformation and ageing of mild steel: III discussion of results. Proc Phys Soc London Sect B 64(9):747-753. https://doi.org/10.1088/0370-1301/64/9/303

44. Kennedy E, Byrne G, Collins DN (2004) A review of high power diode lasers in surface hardening. J Mater Process Technol 155156:1855-1860. https://doi.org/10.1016/j.jmatprotec.2004.04.276

45. Sander J (2018) Selektives Laserschmelzen hochfester Werkzeugstähle. Dissertation, Technische Universität Dresden

46. Kou S (2002) Welding metallurgy, 2nd edn. John Wiley \& Sons, Hoboken

47. Hojati F, Daneshi A, Soltani B, Azarhoushang B, Biermann D (2020) Study on machinability of additively manufactured and conventional titanium alloys in micro-milling process. Precis Eng 62: 1-9. https://doi.org/10.1016/j.precisioneng.2019.11.002

48. Denkena B, Grove T (2016) The effect of microstructure on the machinability of Ti-6Al-4V. In: Proc $13^{\text {th }}$ World Conf Titan, pp 905-910. https://doi.org/10.1002/9781119296126.ch155

49. Schönherr H (2018) Spanende Fertigung. Oldenbourg Wissenschaftsverlag, Berlin

50. Bonaiti G, Parenti P, Annoni M, Kapoor S (2017) Micro-milling machinability of DED additive titanium Ti-6Al-4V. Procedia Manuf 10:497-509. https://doi.org/10.1016/j.promfg.2017.07.104

51. Lizzul L, Sorgato M, Bertolini R, Ghiotti A, Bruschi S (2020) Anisotropy effect of additively manufactured Ti6Al4V titanium alloy on surface quality after milling. Precis Eng 67:301-310. https://doi.org/10.1016/j.precisioneng.2020.10.003

52. Khaliq W, Zhang C, Jamil M, Khan AM (2020) Tool wear, surface quality, and residual stresses analysis of micro-machined additive manufactured Ti-6Al-4V under dry and MQL conditions. Tribol Int:106408. https://doi.org/10.1016/j.triboint.2020.106408

53. Rodrigues AR, Jasinevicius RG (2017) Machining scale: workpiece grain size and surface integrity in micro end milling. In: Microfabrication and Precision Engineering. Elsevier, pp 27-68. https://doi.org/10.1016/B978-0-85709-485-8.00002-4

Publisher's note Springer Nature remains neutral with regard to jurisdictional claims in published maps and institutional affiliations. 